\title{
Investigar, enseñar, difundir: coordenadas actuales del trabajo académico universitario ${ }^{1}$
}

Delia María Crovi Druetta

Profesora Titular C-TC. Facultad de Ciencias Políticas y Sociales, Universidad Nacional Autónoma de México (UNAM). Doctora en Estudios Latinoamericanos. México.

E-mail: crovidelia@gmail.com

Resumen: Se analizan las condiciones actuales de la enseñanza del periodismo y la comunicación a partir de los requerimientos que plantea el ejercicio profesional en los medios digitales. Sostenemos que en la actualidad la epistemología de la comunicación o teoría del conocimiento comunicativo constituye un proceso que enfrenta desafíos al interior del campo y en los sistemas educativos, producto del lugar social que ocupan los medios tradicionales y digitales. El enfoque de estas reflexiones emerge de la consulta de documentos y bibliografía con perspectiva crítica sobre el tema bajo análisis, buscando confrontarlos y establecer líneas de pensamiento para su discusión.

Palabras clave: periodismo; comunicación; educación superior.
Resumo: Este artigo analisa as condições atuais do ensino em jornalismo e comunicação com base nas exigências impostas pela prática profissional nos meios digitais. Afirmamos que, na atualidade, a epistemologia da comunicação, ou teoria do conhecimento comunicativo, constitui um processo que enfrenta desafios no campo e nos sistemas educacionais, produto do lugar social ocupado pelas mídias tradicionais e digitais. É por isso que o foco dessas reflexões emerge da consulta a documentos e bibliografia, com uma perspectiva crítica sobre o assunto em análise, buscando confrontá-los e estabelecer linhas de pensamento para sua discussão.

Palavras-chave: jornalismo; comunicação; educação superior.

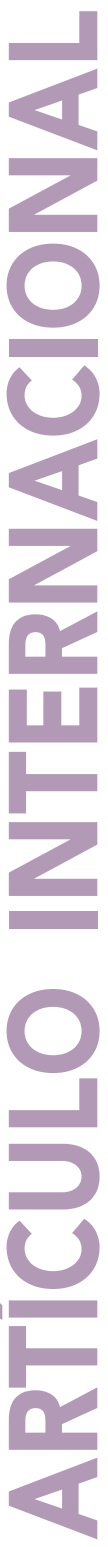

1. Esta es una versión ampliada del artículo presentado en el Grupo de Interés Comunicación y Trabajo, del Congreso de Asociación latinoamericana de Investigadores de la Comunicación, Alaic, 2020.

Recibido: 22/12/2020

Aprobado: 29/12/2020 
comunicação \& educação • Ano XXV • número 2 • jul/dez 2020

\section{ANTECEDENTES Y DELIMITACIÓN DEL TRABAJO}

El propósito de este trabajo es reflexionar sobre las transformaciones que ha experimentado en los últimos años la construcción epistemológica del campo de conocimiento de la comunicación, así como las condiciones de persistencia (o no) de un pensamiento crítico en la producción académica universitaria. El abordaje de estas reflexiones se sustenta en una discusión documental crítica, que abarca los cambios en la enseñanza y en la práctica del ejercicio periodístico, enfatizando las condiciones y retos del presente.

Partimos de dos supuestos iniciales de reflexión. El primero sostiene que en la actualidad la epistemología de la comunicación, o teoría del conocimiento comunicativo, enfrenta desafíos al interior del campo y en los sistemas educativos, producto del lugar social que ocupan los medios tradicionales y digitales. El segundo señala que los parámetros generales impuestos por los cambios en la educación superior, universo de nuestro análisis, se apoyan en criterios productivistas derivados de las ciencias exactas, que están lejos de comprender y valorar tanto la enseñanza del periodismo como de otras producciones comunicativas. Tampoco facilitan los procesos investigativos y de difusión de estos temas, situación que conduce a una paradoja: en la medida en que los medios analógicos o digitales alcanzan una posición destacada en las dinámicas sociales, se amplía la agenda de investigación de nuestro campo, pero decrecen los recursos para abordarla ${ }^{2}$.

De estos supuestos se desprenden dos objetivos generales, con el fin de abordar críticamente esta problemática.

1. Analizar el proceso de transformación experimentado por la educación superior (con énfasis en América Latina), destacando nuevos sistemas de evaluación para la labor docente, institucionalización de la investigación comunicativa con injerencia en las agendas de trabajo, sistemas de becas que benefician a investigadores y alumnos, escasa renovación de la planta académica, nuevos proveedores educativos, entre otros, con el fin de identificar el contexto actual en que se desarrollan docencia e investigación de la comunicación.

2. Reflexionar sobre la incidencia que el cambio en la educación superior tiene en la formación de comunicadores y periodistas, considerando que se trata de un ámbito profesional dinámico, profundamente transformado a partir de la digitalización (nuevos líderes informativos, periodismo espontáneo en competencia con el profesional, noticias falsas o sin fuentes fiables, desdibujamiento de los géneros, etc.).

mutaciones sustantivas En lo económico, destaca la crisis de alcance mundial del 2008, misma que para algunos analistas estamos a punto de replicar en el presente, amenzado con recesión y un regreso a la hegemonía de la derecha en el poder.

2. Para estas reflexiones cana en la que desarrollo mi trabajo académico, pero riencias regionales de carácter similar. En todas ellas común denominador es a crisis, y toda crisis re fiere un momento difícil, en el cual se producen 
que ha llegado para quedarse entre digitalización y producción del saber. Para esa relación enfocaré estas reflexiones situándolas en el ámbito universitario.

Entre los años 1960 y 1970, desde distintos países, emergen propuestas cimentadas en la producción y circulación social del saber. Entre las cuales, destaca la contribución de Fritz Machlup ${ }^{3}$, quien publica Production and distribution of knowledge in the United States. En esta obra identifica al conocimiento como un dato, un producto que puede ser analizado considerando las fases del círculo productivo: producción y distribución; adquisición y transmisión; y creación y comunicación. Años más tarde, este autor señala cinco sectores económicos que considera básicos: educación, medios de comunicación, máquinas de información, servicios de información y otras actividades de información que pueden medirse si se les asigna un valor económico. Este señalamiento es singular, ya que, salvo la educación, los demás sectores apenas estaban emergiendo.

En ese mismo año, Daniel Bell ${ }^{4}$ presenta su concepto de sociedad posindustrial, propuesta según la cual los procesos industriales cedían su destacado lugar a la información. Bell adelantó entonces que para la sociedad de finales del siglo XX la preocupación central sería el futuro, así como la consideración de que el conocimiento es un factor productivo y prioritario de su control para la toma de decisiones.

Una década después, en 1972, Yoneji Masuda ${ }^{5}$ defendía un futuro marcado por la productividad informativa. Vislumbraba para Japón, su país, una fuerte influencia de la computación y de la información.

Además de esos autores, otros pensadores coincidieron, desde sus perspectivas personales y locales, en destacar la importancia de una sociedad que cuyo centro es la información y el conocimiento, lo que daría lugar a un enunciado ahora aceptado: sociedad de la información y el conocimiento. Este tipo de sociedad coadyuva en el desarrollo global del modelo político-económico neoliberal, que se implanta a comienzos de la década de los 1980.

Como producto de tales cambios de sentido, a finales del siglo XX se dan a conocer propuestas internacionales para la educación superior. Sus consecuencias se reflejan en una marcada reducción de presupuestos destinados a universidades públicas, lo que las lleva a abrirse camino mediante el cobro de matrículas o de algunos servicios educativos, orientando la investigación según las agendas y financiamientos disponibles. Este proceso conduce a descuidar la renovación de las plantas académicas, ya que cuando se liberan algunos lugares de trabajo, la tendencia es no reponerlos. En conjunto, estas medidas pueden ser vistas como una privatización parcial de la educación.

En materia de investigación, estas transformaciones miden y profundizan la relación entre el financiamiento de los estudios realizados en el ámbito académico y el logro de resultados, patentes o productos tangibles. Tales mediciones contabilizan la producción, alimentando un sistema de premios y castigos consistente en becas de productividad, concursos para el financiamiento a proyectos, sistemas de reconocimiento económico a los científicos que proporciona ingresos paralelos a los salarios universitarios.
3. MACHLUP, Fritz. The production and distribution of knowledge in the United States. Princeton: Princeton University Press, 1962.

4. BELL, Daniel. El advenimiento de la sociedad post-industrial. Madrid: Alianza Editorial, 2006.

5. MASUDA, Yoneji. The information society as post-industrial society. Chicago: World Future Society, 1981. 
En paralelo, se fomenta la creación de instituciones de educación superior privadas, con fines de lucro, cuyas costosas matrículas son asumidas por sus alumnos ${ }^{6}$. Solo algunas conservan la misión de saber universal que caracteriza a las universidades tradicionales, produciendo resultados en investigación y docencia, aunque muy cercanos a las demandas de mercados nacionales e internacionales. Estas nuevas instituciones, no obstante, llenan vacíos del sector educativo público, incapaz de cubrir la demanda creciente de alumnos.

Previo a estos cambios, las universidades había sido uno de los eslabones más preciados en la transformación científico-tecnológica, así como actores en la formulación de políticas públicas. Fue en ese ámbito en que se desarrolló y enriqueció la epistemología de la comunicación. Sin embargo, con el neoliberalismo se reconfigura la producción de conocimiento y el lugar social de las instituciones de educación superior, propiciando que las agendas de investigación respondan a las necesidades de los sectores productivos, mientras se descuida la ciencia básica. Este panorama repercute negativamente en las ciencias sociales, ya que ante el nuevo esquema sus resultados son intangibles y difícilmente generan patentes. Al mismo tiempo, las agendas de investigación se orientan según financiamientos que suelen estar alejados del interés de los investigadores. Tal es el caso del periodismo visto solo desde la economía política para reconocer la movilidad de las empresas que intervienen, o desde el desarrollo de habilidades para formar periodistas capaces de cubrir con su trabajo la totalidad del proceso informativo (desde el registro o fuente original hasta su emisión, pasando por procesos técnicos).

En los orígenes de las carreras de grado y posgrado en comunicación, el periodismo fue objeto central de enseñanza e investigación. Sin embargo, en el presente se desdeña el estudio de su impacto social, así como de los procesos informativos. Los temas ahora cobran actualidad a partir de expresiones en las redes sociales: noticias falsas, opiniones disfrazadas de nota informativa, tendencia a la espectacularización de los sucesos, amarillismo, el humor como recurso de ataque o de desinformación, entre otros.

En medio de este panorama, destaca también un cierto desapego hacia las instituciones de investigación académica tradicionales, lo que deriva en la existencia de universidades desinteresadas en la investigación y la formación de científicos, en tanto que otras carecen de recursos para la investigación. El sistema de medición de la productividad instaura una práctica: cada investigador debe gestionar sus propios recursos, apoyándose en programas que los concursan.

6. SILVIO, José. La virtualización de la universidad: ¿Cómo transformar la educación superior con la tecnología? Caracas: lesalc, 2000

\section{LA FORMACIÓN DE PERIODISTAS Y COMUNICADORES}

El segundo objetivo de este texto se refiere a la formación de periodistas y comunicadores, que no ha sido ajeno a las transformaciones que han experimentado las universidades. Lejos están los tiempos en que el periodismo ocupara el interés prioritario del campo de la comunicación, entonces incipiente. Como nos ha pasado ante temas diversos, al ampliarse las agendas comunicativas en 
la docencia y la investigación, decae el interés por lo periodístico. Hay muchas críticas al desempeño profesional por alinearse a ciertos intereses económicos o políticos, recibir sobornos o autocensurarse, algo que en parte deviene de los bajos salarios que reciben, por lo que deben trabajar en varios medios simultáneamente y, en algunos casos, recibir pagos por la orientación de la información que difunde.

Como es sabido, el mayor desafío del ejercicio profesional del periodismo deriva de la robustez de las redes sociales digitales que representan y se defienden como canales para la expresión de los ciudadanos, más allá de los medios. El impacto de las redes es importante tanto para la formación del periodista como para el respeto al proceso informativo que orientaba su desempeño profesional. Además, la riqueza de las redes es indiscutible porque da cabida a interpretaciones alternativas de los sucesos, puntos de vista diferentes, pero también suelen recurrir al amarillismo, a ataques verbales personalizados o no, mensajes agresivos y, en ocasiones, acoso físico a otros miembros de esas redes. En consecuencia, violentan los más elementales preceptos éticos que fueron parte del periodismo de antaño.

La defensa de la libertad de expresión ha hecho permisivas a las redes sociodigitales que pueden difundir o replicar mensajes sin comprobar su contenido, sin fuente, sin la más mínima precaución para verificar lo que se dice. El objetivo suele ser ganar seguidores a costa de la verdad o del profesionalismo que requiere una actividad de gran importancia social como el periodismo. La emergencia de voces que ganan seguidores en la redes produce una falsa disputa entre la libertad de expresarse y la responsabilidad de informar de manera profesional. Youtubers, influencers, twitteros, contenidos cómicos que deforman los hechos sociales y los ridiculizan, así como otros líderes de opinión en redes, defienden su libertad de decir sin más sustento que el número de seguidores.

Formar profesionales del periodismo para esta realidad, donde los influencers de redes sociales ganan cifras altísimas si se los compara con los ingresos periodísticos, constituye un desafío ético y profesional. Además, la práctica del soborno, conocida en México como "chayote", es otro factor que atenta contra la profesión y la deforma. Están también los temas tabús sobre los cuales no se puede informar, a riesgo de poner en peligro la vida del comunicador o la de sus familiares.

Desde las aulas se pueden enseñar las normas del periodismo, como marco teórico para una realidad que se aleja bastante de ellas. La dicotomía entre teoría y realidad, paradójicamente, es ahora mayor como producto de algo que buscamos durante décadas: nuevos medios para expresarnos.

Tenemos derecho a seguir pensando que la universidad sea el ámbito primario de la producción y reproducción del conocimiento. Hasta no hace mucho lo era. Con la formidable expansión de las universidades y de su población estudiantil, una de las cosas que ha ocurrido es lo que llamaría la gran escolarización del sistema universitario, esto es, la enorme presión social ${ }^{7}$.
7. WALLERSTEIN, Immanuel. Abrir las ciencias sociales: informe de la Comisión Gulbenkian para la reestructuración de las ciencias sociales. Ciudad de México: Siglo Veintiuno Editores, 2006, p. 8. 
En efecto, las universidades tienen desafíos mayores que afrontar en relación a sí mismas, a la producción del saber y su circulación. Sabemos que estos retos superan al campo de conocimiento de la comunicación, sin embargo, los de este campo no son menores: afectan a los sujetos que intervienen, los medios que se emplean, así como el sentido y características de las prácticas que desarrollan los periodistas. Su incidencia social no es discutible, tanto que en la segunda década del siglo XXI hasta la fortaleza de las democracias dependen de sus periodistas y sus medios tradicionales o digitales.

Las universidades deben trabajar en el esclarecimiento de su lugar social y en la producción y difusión del conocimiento. También deben pensarse a sí mismas como instituciones, encarando una reflexión profunda sobre su papel cultural, social y político, y las responsabilidades derivadas de esos roles.

En relación al segundo objetivo planteado aquí, es necesario no solo analizar los cambios operados en los últimos lustros, sino considerar de manera muy especial lo que estamos viviendo actualmente como consecuencia del Covid-19.

En América Latina, la educación superior ha padecido crisis recurrentes derivadas de decisiones coyunturales y, a veces, erráticas de los gobiernos, que han aplicado políticas públicas alejadas de las condiciones en que se enseña, se investiga y difunde el saber. Si bien esta presentación trata específicamente del campo de conocimiento de la comunicación, este comparte con otras áreas del saber -las ciencias sociales de manera destacada-, muchos de los desafíos y cambios que, desde finales del siglo pasado, enfrentan la enseñanza e investigación universitaria.

Los cambios más notorios en la educación superior tienen origen en la globalización neoliberal (años 1980) cuando los organismos internacionales comienzan a proponer lineamientos que buscan una restructuración profunda, ligándola a un saber instrumental que responde a lógicas del mercado. Con características peculiares según su nivel de desarrollo y condiciones materiales, dichas líneas de acción se comparten en casi todo el mundo. Nuevos marcos legales facilitan esos cambios, y causan una migración constante de alumnos y docentes desde los sistemas públicos de enseñanza a los privados.

También corresponde a estos años el proceso de institucionalización de la investigación, cuyos ejes de transformación tocan a alumnos, a maestros y a la propia institución educativa. Para los alumnos del nivel superior y posgrado, se crean sistemas de becas, que por un lado buscan palear la falta de empleos y, por otro, conforman un sistema de control con miras a asegurar titulaciones en tiempo y forma, aumentar la eficiencia terminal y evitar deserciones. Este conteo de alumnos titulados se inserta en la tendencia de cuantificar logros y fracasos.

En cuanto a los maestros, se crea un sistema de productividad basado en premios y castigos, que igual garantiza recursos para la investigación y la difusión, castiga su falta de interés por ese tipo de productos o sus posturas críticas. Los premios para los docentes suelen estar condicionados a seguir agendas establecidas de investigación, mostrar compromiso institucional acrítico y 
demostrar su capacidad para trabajar en equipo. Todos estos aspectos conducen al alejamiento, en mayor o menor medida, del pensamiento crítico a docencia, investigación y difusión.

El docente-investigador de comunicación, periodismo y todas las áreas de conocimiento tiene ahora que hacer muchos informes que cuantifican su producción, misma que redunda en beneficios económicos otorgados en forma de estímulos, becas, asistencia a congresos y financiamiento para investigar, en los cuales se suele reproducir un sistema clientelar que proscribe el pensamiento crítico. La docencia descansa en trabajos parciales o por horas, con maestros que tienen escasas posibilidades de desarrollar una carrera académica. Hay muchos que desempeñan su actividad profesional principal fuera del sistema universitario: guionistas, periodistas, productores, conductores, youtubers, managers, etc.

En paralelo, emergen nuevos proveedores educativos del sector privado, instituciones donde las becas para alumnos son escases o inexistentes, en tanto que la investigación académica es casi nula, salvo que se trata de productos patentables. Cabe enfatizar que, con distintas variantes, la educación privada siempre ha existido, y a partir del modelo neoliberal se expande por ser parte de la liberalización que impone el libre juego de oferta y demanda. Se pasa del modelo de financiamiento de control del Estado a un modelo de supervisión estatal. En el primer caso de origen francés, el Estado entiende a la educación superior como un elemento fundamental del desarrollo social, por lo que asume sus costos, delinea sus metas, objetivos, sistemas de titulación, permanencia y egreso. En el segundo modelo de origen británico y estadounidense, cada institución propone y desarrolla sus propios programas y organización, con una participación secundaria del Estado. En este caso el financiamiento proviene del mercado ${ }^{8}$.

Con el cambio de modelo que buscaba la reproducción del sistema, los contenidos de la educación superior controlados por el Estado se diversifican y dispersan, fortaleciendo una nueva visión del mundo: el modelo de libre mercado con el individuo y la familia como ejes del nuevo orden. El proceso privatizador de la enseñanza superior tiene, así, el efecto de profundizar el discurso neoliberal mediante los nuevos proveedores: favorece la coincidencia de metas entre las argumentaciones del modelo y sus propios intereses.

De esta manera, desde finales de los 1990 el modo de producción científica cambia: se fue abandonando el modelo de producción lineal (dominante a partir de la Segunda Guerra Mundial) en el cual el conocimiento se produce en instituciones del sector educativo, en un segundo paso se divulga y son las empresas las que transforman esas innovaciones en productos o servicios que al final llegan a la población o consumidor. Este ciclo hizo de las universidades y sus procesos de investigación protagonistas del cambio tecnológico y la innovación científica, pero la ruptura de esta linealidad en la producción del conocimiento puso en entredicho su lugar social. Con la pandemia del Covid19, la ciencia recobró un lugar de importancia como fuente de información creíble, pero junto con este reconocimiento llegó la llamada infodemia que 
desata noticias falsas, facilita la copia sin fuentes, promueve discusiones estériles e irreconciliables, de puntos de vista diferentes. También las predicciones y modelos matemáticas se colocan como verdades indiscutibles cuando son solo eso: predicciones.

Para la comunicación, la existencia de universidades sin interés en la investigación básica, y otras con presupuestos escasos o que condicionan el desarrollo de estudios de largo alcance, constituye un desafío de múltiples aristas. Es notoria la creciente oferta de carreras con contenidos comunicativos de corte instrumental. También es visible la histórica desatención del campo, tanto en el ámbito de las ciencias sociales como en el saber científico general. A pesar de su posicionamiento social y su incidencia en las prácticas culturales de los individuos, aún padecemos de invisibilidad y poco reconocimiento sobre la importancia de los fenómenos comunicativos.

La situación de la enseñanza y la investigación del periodismo repercute en los contenidos de la enseñanza y preocupa la actualidad de los contenidos que se ofrecen. ¿Cómo formar para el periodismo ciudadano?, ¿cómo atender la demanda de formación que emerge desde otros líderes informativos (youtubers, influencers, twitteros, bots sin emisores visibles, algoritmos, entre otros)?, ¿cómo señalar los caminos para combatir noticias falsas, informaciones o comentarios sin fuentes, mezcla de géneros que suele pasar inadvertida entre las audiencias, pero que al fin y al cabo forman su opinión?

La supuesta caja de cristal en la que la academia vivió, o se le acusa de vivir, es ahora más estrecha y tiende a resquebrajarse. Cada uno debe gestionar recursos propios para producir y difundir el conocimiento, acomodándose en las agendas hegemónicas.

\section{LOS DESAFÍOS ACTUALES DE ENSEÑANZA UNIVERSITARIA}

Con una planta docente envejecida o poco comprometida con la academia porque está integrada por maestros por hora, interinos, ocasionales, cuyos ingresos dependen de otras actividades, la enseñanza del periodismo y la comunicación cursa por caminos difíciles de afrontar en tiempos digitales de cambios vertiginosos.

Esto, que en realidad debería ser una preocupación mayor, en estos momentos se coloca apenas como el telón de fondo de una realidad que nos ha superado: el singular aislamiento durante la pandemia del Covid-19 que trajo como consecuencia la digitalización (a mi juicio improvisada y descuidada) de la educación superior. Es comprensible si la vemos como un camino corto para evitar la parálisis social experimentada en casi todo el mundo, no obstante, desconocemos sus consecuencias. Como todo cambio, algo habrá llegado para quedarse, pero no debe ser un proceso tan simplista ni espontáneo: debemos darnos el tiempo necesario para registrar, reflexionar y proponer modelos innovadores de enseñanza. 
Si la vemos desde la relación trabajo-educación superior, tenemos tres factores encadenados que pueden llevar a la ausencia de un pensamiento crítico, sensato y creativo, sobre este vínculo. Ese encadenamiento se da primero con la irrupción del virus, enseguida se produce la digitalización de la vida cotidiana (marcadamente del trabajo, la educación y el consumo), y como corolario una gran crisis económica derivada de las etapas anteriores. Cada paso requiere análisis, mirando su evolución desde la relación trabajo-educación superior.

Para esta generación, incluso en el momento que enviamos los resúmenes para participar en el congreso ALAIC 2020, no había indicios que previnieran sobre la actual pandemia. Hasta entonces teníamos referentes históricos de otros contagios colectivos, peligrosos y mortales, pero no eran más que eso: referentes de otros tiempos imposibles de pensarse en el siglo XXI con el avance científico disponible. No obstante, surgieron temas de investigación que se pueden considerar necesarios para pensar en este ámbito académico:

1. Sistemas de salud desmantelados por un modelo impuesto en los años 1980: la globalización neoliberal centrada en la privatización y achicamiento del Estado, justo donde se ubica el sector salud y también el educativo. Ambos fueron privatizados total o parcialmente, con los resultados que observamos en la segunda década del siglo y sin que la comunicación o el periodismo haya advertido adecuadamente su magnitud.

2. Una investigación científica desvinculada de las necesidades sociales, subsidiaria de modas y temas propuestos globalmente que poco tienen que ver con las necesidades sociales. Este proceso, que también contaminó a nuestra área de conocimiento, nos encuentra, por ejemplo, con escasa formación docente para la digitalización o un trabajo crítico respetable en las redes sociales digitales.

3. Un periodismo que para entonces ya había perdido, en buena medida, el interés investigativo y el interés por el trabajo de campo, perspectiva que lo lleva a canalizar la información, prioritariamente, hacia dos formatos: la copia como "refrito" y el punto de vista personal bajo el "artículo de opinión”. La copia es la falta de respeto a las fuentes originales, la ausencia de trabajo empírico (demostrado en la pandemia), la forma usada en exceso para decir de otro modo información producida por alguien más, algo que también ocurre en la producción académica. Dos factores inciden en esta tendencia que copiar: el trabajo todo terreno promovido en el periodismo que busca obtener más ganancias, y el acceso a redes sociales e Internet como medios que permiten expresar ideas y puntos de vista a quienes tienen acceso, de manera más o menos libre, lo que suele conducir a la incertidumbre y al caos informativo. En cuanto al formato de opinión, es evidente que en muchas ocasiones es solo eso: opinión personalizada sin recurrir a consulta de fuentes, respaldo de datos, fuentes confiables o trabajo empírico. La nota de opinión ha sido incentivada desde las empresas mediáticas para contar 
entre sus contenidos con nombres que creen distinguirlos y que evitan las condiciones de un reportero de planta con los derechos legales que le corresponden. En la práctica, sin embargo, el abuso de la opinión ha convertido a este recurso en un instrumento de acoso y denuncia personalizado posicionándolo como un mecanismo para el agravio y la denuncia ligada a intereses políticos, ideológicos y económicos.

En cuanto a los procesos de digitalización, otro paso que se agrega a este esquema simplificado en tres etapas ha surgido como la solución a la parálisis social que se vivía, lo que no le quita un estigma de improvisación. De repente, irrumpe sin pensarse previa y seriamente en dos ejes del proceso digital: una nueva dimensión de tiempo y espacio, subestimados antes en la educación superior a distancia. A mi juicio, debemos pasar de la anécdota del gato o un personaje desnudo apareciendo en una transmisión educativa o periodística, a registrar y analizar la experiencia. Un registro y un análisis en el que todos los actores participantes deben intervenir.

El registro, con todo lo positivo y negativo que arroje, puede dar luz para responder a varias preguntas pendientes. ¿Están todos los hogares dotados de espacios suficientes para albergar este mundo a domicilio? ¿Existen tiempos sin superposiciones entre quien estudia, quien trabaja, quien descansa o está enfermo en una misma vivienda? La crisis de ruptura de fronteras espaciales y temporales se hizo evidente, sobre todo entre quienes tienen menos recursos. Están además las conexiones obsoletas o insuficientes, los aparatos que no soportan ciertos programas y que, además, no siempre son de acceso y uso individual, sino que se comparten en familia.

Cuando en las propuestas de la sociedad de la información se aceptó la existencia de brechas, pensadas al principio en su dimensión tecnológica y ampliada luego a otros aspectos (capital cultural, nivel educativo, lugar de residencia, género, entre otros), se estaba reconociendo que la digitalización representaba la reproducción de las condiciones estructurales de ciudades, pueblos, regiones y países. Casi 30 años después, el Covid-19 les ha dado la razón.

\section{REFLEXIONES FINALES}

El panorama trazado indica vicisitudes para el futuro inmediato de las universidades en sus funciones históricas básicas. Si entendemos por revolución un cambio de grandes dimensiones en la organización social, la digitalización puede ser eso. Las universidades forman parte de esta revolución, por lo tanto, están en el curso de transformaciones profundas que no tienen una salida inmediata, sino que exigen políticas y programas acordes a la dimensión de los cambios que experimentan.

Las nuevas dinámicas sociales, digitales y neoliberales han colocado a las instituciones de educación superior en un lugar diferente al que tenía desde 
hace unos 70 años, más otras dinámicas heredadas del siglo XIX. Su propio sentido y lugar social se han puesto en tela de juicio, por lo que sus sistemas de comunicación no pueden permanecer al margen de tales vicisitudes. Para que el dato brindado por la información se pueda transformar en conocimiento superior, transformador del entorno social, es necesario que las universidades sigan alimentando el pensamiento crítico en sus comunidades.

La digitalización es parte de una sociedad del conocimiento que, aunque constituye un proyecto inacabado, se la toma como referente y utopía que alcanzar. Desde esta quimera, la comunicación digital es una realidad tangible que modifica sus medios y sus actores, de manera concreta, en prácticas sociales y culturales.

Un nuevo ecosistema comunicativo confronta a la comunicación universitaria desde varios frentes. Los cuatro ejes mencionados para pensar este novedoso ecosistema son importantes pero no únicos. Cada institución tendrá además sus propias preocupaciones, sus conquistas y sus pendientes. Por ello, es menester que las reflexiones sobre esos desafíos no sean colaterales, sino que califiquen como un gran cambio cultural que opera en todas las actividades universitarias, haciéndolas interdependientes.

Pensar solo en el acceso, ofreciendo equipos y programas actualizados, es apenas uno de los retos de las instituciones de educación superior ante lo digital. Pero las verdaderas batallas se desarrollan en el campo de las transformaciones culturales y en las prácticas sociales que se han señalado anteriormente. Hacia allí cada universidad debe orientar sus reflexiones.

En sus condiciones actuales, la educación superior cuestiona el lugar histórico de las universidades como productoras del conocimiento, incluidos el periodismo y la comunicación. En el ejercicio periodístico ello se traduce en un desconocimiento del valor formativo de los sujetos que ejercen esta actividad, que lleva al desconocimiento de la importancia de las fuentes informativas, el valor de los géneros entendidos como un horizonte de espera que orienta a las audiencias sobre los contenidos que recibe, entre otros aspectos.

Estas prácticas unidas al desarrollo digital son las que están llevando a los nuevos comunicadores/periodistas a confundir información con opinión, y lo que es más preocupante, malinterpretar o inventar contenidos informativos que generan las llamadas noticias falsas. Asimismo, la práctica frecuente del acoso a periodistas y audiencias mediante mensajes directos agresivos, memes, $\mathrm{u}$ otros recursos usados con frecuencia para ejercer el bullying, limita la perspectiva crítica.

Se suma a esta desviación informativa un claro desplazamiento de las audiencias desde una programación estructurada en tiempos fijos, como las de la radio o televisión, hacia el streaming que hace uso de la nueva dimensión espacio-tiempo propiciada por la digitalización, llevando a un consumo audiovisual personalizado que impacta en la construcción de agendas públicas y críticas.

¿Cómo enseñar prácticas informativas acordes a los tiempos presentes? Tanto el desplazamiento del histórico papel que las universidades han jugado 
en la construcción del conocimiento y su divulgación, como el cambio social vertiginoso constituyen un reto mayúsculo para enseñar periodismo.

En apariencia, las prácticas sociales vuelven obsoleto cualquier conocimiento que hubiéramos atesorado en tiempos pasados. Sin embargo, volver a esas fuentes y reactualizarlas a la luz de las prácticas actuales es uno de los grandes desafíos debido a que los ejes del conocimiento sobre el periodismo y la comunicación persisten y constituyen la fuerza de su ejercicio profesional.

\section{REFERENCIAS BIBLIOGRÁFICAS}

ALMENARA, Julio Cabero. Nuevas tecnologías, comunicación y educación. Comunicar, Huelva, n. 3, p. 14-25, 1994.

APARICI, Roberto. Educomunicación: más allá del 2.0. Barcelona: Gedisa, 2010 .

BELL, Daniel. El advenimiento de la sociedad post-industrial. Madrid: Alianza Editorial, 2006.

COMBONI, Sonia; JUÁREZ, José Manuel; POMBO, María Dolores París. ¿Hacia dónde va la Universidad Pública? La educación superior en el siglo XXI. Ciudad de México: Universidad Autónoma Metropolitana Xochimilco, 2002.

DRUETTA, Delia Crovi. Redes sociales digitales: lugar de encuentro, expresión y organización para los jóvenes. Ciudad de México: Unam, 2016.

LÉVY, Pierre. Cibercultura: la cultura de la sociedad digital. Barcelona: Anthropos, 1999.

MACHLUP, Fritz. The production and distribution of knowledge in the United States. Princeton: Princeton University Press, 1962.

MASUDA, Yoneji. The information society as post-industrial society. Chicago: World Future Society, 1981.

SILVIO, José. La virtualización de la universidad: ¿Cómo transformar la educación superior con la tecnología? Caracas: Iesalc, 2000.

WALLERSTEIN, Immanuel. Abrir las ciencias sociales: informe de la Comisión Gulbenkian para la reestructuración de las ciencias sociales. Ciudad de México: Siglo Veintiuno Editores, 2006. 